\title{
ARTICLE \\ Comparison of new medial linkage reciprocating gait orthosis and isocentric reciprocating gait orthosis on energy consumption in paraplegic patients: a case series
}

\author{
M Ahmadi Bani ${ }^{1}$, M Arazpour ${ }^{1}$, F Farahmand ${ }^{2}$, RV Kashani ${ }^{1}$, ME Mousavi ${ }^{1}$ and SW Hutchins ${ }^{3}$
}

OBJECTIVES: As energy consumption during orthotics walking has main role in rehabilitation of walking in individuals with spinal cord injury $(\mathrm{SCl})$, the aim of this study was comparison between new medial linkage orthosis (new MLO) and isocentric reciprocating gait orthosis (IRGO) on energy consumption in paraplegic patients.

METHODS: Four people with motor incomplete SCI (mean age 34.5 years, mass $73 \mathrm{~kg}$ and height $175 \mathrm{~cm}$ with injury levels ranging from T8-T12) participated in this study. Gait evaluation was performed using new MLO compared with using conventional IRGO. Walking speed and heart rate were measured to calculate the physiological cost index $(\mathrm{PCl})$ to estimate metabolic energy consumption.

RESULTS: Reductions in energy consumption were observed using new MLO compared with using IRGO, but the difference was not statistically significant. However, walking distance and walking speed also improved, but not significantly.

CONCLUSION: All subjects had faster speeds of walking, walked longer distances and had lower PCI when using new MLO compared to walking with IRGO. Consequently, this orthosis should be examined and considered with larger sample size.

Spinal Cord Series and Cases (2015) 1, 15012; doi:10.1038/scsandc.2015.12; published online 8 October 2015

\section{INTRODUCTION}

Addressing the high-energy expenditure in paraplegic subjects during ambulation is one of the most important challenges for patients and therapist. ${ }^{1,2}$ About half of paraplegic patients do not use orthoses for standing and walking and the remainder use assistive devices as exercise equipment, because of the high energy consumption required to ambulate with these devices. Understanding the causes of high-energy expenditure would be useful for finding ways to reduce it. ${ }^{3-5}$

Powered, mechanical and hybrid orthoses are three types of devices for walking and standing in spinal cord injury (SCl) patients. ${ }^{6}$ Arazpour et al. ${ }^{7}$ reported reduction of the energy expenditure by powered orthoses than a mechanical orthosis in source of energy for activation of lower limb. Kawashima et al. ${ }^{8}$ evaluated their new weight-bearing control orthosis and reported that it enables patients to walk with higher speeds under similar energy expenditure and considered that it would improve energy cost of walking in paraplegic patients. Although powered gait orthosesreduce energy expenditure in $\mathrm{SCl}$ patients compared with mechanical orthoses, these types of orthoses are restricted to laboratory environments and patients do not actually use them at all in the community. ${ }^{9}$ Researchers believe that mechanical orthoses are still superior than others because they are more user friendly and they have simple mechanism. There are three groups of mechanical orthoses (traditional orthoses, reciprocating gait orthoses (RGOs) and medial linkage orthoses (MLOs)), of which the last two groups have special advantages. RGOs have a mechanism for reciprocating movement and MLOs are light and more user friendly. ${ }^{10}$ Notable limitations of isocentric RGOs (IRGOs) include the restriction of torso motion, which increases the difficulty for performing activities of daily living, and the heavy and bulky configuration that indicate an unacceptable design and structure of orthosis. ${ }^{10}$ MLOs do not provide a reciprocating effect when used during ambulation, which would be advantageous for $\mathrm{SCl}$ patients. To provide a more advanced mechanical orthoses, incorporating a combination of the MLO and RGO features, recently a new mechanical orthoses has been introduced by corporation of advantages of two groups. ${ }^{11}$

The new MLO was developed based on the concept of changing the source of energy for activating the lower limbs. In the new MLO, pelvis motion was used for creating the hip flexion and forward limb motion during ambulation, whereas trunk support was achieved by a more flexible lumbo-sacral-orthosis. ${ }^{11}$ Bani et al. ${ }^{12}$ evaluated the effect of the new MLO and reported the superiority of this new orthosis compared with IRGO in paraplegic patient. This study has demonstrated that this new mechanism is a valuable means for patients' ambulation because it creates higher torque for hip flexion and walking while demonstrating acceptable gait parameters. Its weight is half that of an IRGO.

Regarding to the new orthosis has a mechanism for reciprocal motion and reduces orthotic bulk and weight would further reduce energy consumption, we hypothesized that walking with the MLO would decrease energy expenditure of walking. As energy consumption during orthotics walking has a primary role in the rehabilitation of walking in $\mathrm{SCl}$ patients, therefore the aim of this study was comparison energy expenditure of the new MLO and IRGO in four paraplegic patients as a case series.

\footnotetext{
${ }^{1}$ Department of Orthotics and Prosthetics, University of Social Welfare and Rehabilitation Science, Tehran, Iran; ${ }^{2}$ Department of Mechanical Engineering, Sharif University of Technology, Tehran, Iran and ${ }^{3}$ Faculty of Health and Social Care, University of Salford, Salford, UK.

Correspondence: Dr M Arazpour (M.arazpour@yahoo.com)

Received 2 June 2015; accepted 2 June 2015
} 
Table 1. The characteristics of participated subjects in this study

\begin{tabular}{lccccccc}
\hline & Gender & Age (years) & Height $(\mathrm{cm})$ & Mass $(\mathrm{kg})$ & Level of injury & ASIA score & Time since injury (months) \\
\hline Subject 1 & F & 20 & 165 & 54 & T10 & B & 49 \\
Subject 2 & M & 37 & 187 & 85 & T12 & B & B \\
Subject 3 & M & 54 & 185 & 95 & T8 & B & 41 \\
Subject 4 & F & 27 & 163 & 58 & T6 & & \\
Mean & & 34.5 & 175 & - & & & 38 \\
\hline
\end{tabular}

Abbreviation: ASIA, American Spinal Injury Association. B denotes sensory but not motor function is preserved below the neurological level and includes the sacral segments $S_{4}-S_{5}$.

Table 2. Comparison of distance walked, walking speed and $\mathrm{PCl}$ during the two conditions

\begin{tabular}{|c|c|c|c|c|c|c|c|c|c|c|}
\hline & \multicolumn{2}{|c|}{$\begin{array}{c}\text { HRss } \\
\text { (beats } \min ^{-1} \text { ) }\end{array}$} & \multicolumn{2}{|c|}{$\begin{array}{c}\text { HRar } \\
\text { (beats } \text { min }^{-1} \text { ) }\end{array}$} & \multicolumn{2}{|c|}{$P C l$ (beats $\mathrm{min}^{-1}$ ) } & \multicolumn{2}{|c|}{ Speed of walking $\left(\mathrm{m} \mathrm{min}^{-1}\right)$} & \multicolumn{2}{|c|}{ Distance walked $(m)$} \\
\hline & IRGO & New MLO & IRGO & New MLO & IRGO & New MLO & IRGO & New MLO & IRGO & New MLO \\
\hline Subject 1 & 105 & 98 & 90 & 92 & 0.71 & 0.23 & 21 & 25.2 & 126 & 151 \\
\hline Subject 2 & 110 & 102 & 86 & 84 & 1.05 & 0.66 & 22.8 & 27 & 136 & 162 \\
\hline Subject 3 & 109 & 96 & 84 & 82 & 0.3 & 0.61 & 19.2 & 22.8 & 115 & 136 \\
\hline Subject 4 & 125 & 118 & 92 & 90 & 1.83 & 1.37 & 18 & 20.4 & 108 & 122 \\
\hline Mean & & & & & $0.972 \pm 0.64$ & $0.717 \pm 0.475$ & $20.25 \pm 2.10$ & $23.85 \pm 2.87$ & $121.25 \pm 12.31$ & $142.75 \pm 17.46$ \\
\hline
\end{tabular}

Abbreviations: HRss, heart rate during steady state walking; HRar, heart rate at rest; IRGO, isocentric reciprocating gait orthosis; MLO, medial linkage orthosis; $\mathrm{PCl}$, physiological cost index.

\section{MATERIALS AND METHODS}

Patients

Four individuals with T6-T12 spinal cord lesions with lower limb paralysis and prior IRGO users participated in the study. The patients were incomplete (level B) based on the American Spinal Injury Association score. Inclusion criteria included of the following: no evidence of cardiovascular or pulmonary diseases, contractures, severe spasticity, obesity or asymmetric hip positions. All patients who participated in this study signed consent forms. The present study was approved by the ethics committee of University of Social Welfare and Rehabilitation Sciences. Table 1 shows demographic information of subjects in this study.

\section{Orthotic consideration}

Two different orthotic interventions (IRGO and new MLO) were used in this study. All patients were IRGO users (they were trained to walk by RGO for a minimum of 8 weeks before starting this study) with drop lock joint and dorsiflexion assist ankle joints. A rocker link behind the pelvic section provided reciprocating motion in the IRGO.

A new MLO was designed and fabricated that utilized a four-bar reciprocating mechanism to create a virtual axis of rotation in a more proximal position than typical hinge-type joints. This new orthosis therefore potentially enables a $\mathrm{SCl}$ patient walks at a faster speed and with long step lengths when compared with a mechanical IRGO. The new hip joint with saddle added to a pair of knee-ankle-foot orthoses. A soft lumbo-sacral-orthosis was added for patients with weak muscular support in the trunk. The new MLO is designed to be activated by pelvis motion; unloading one leg and posterior pelvic tilt will propel the leg forward.

The orthoses that were used in this study are shown in Figure 1.

\section{Training}

All patients attended a walking and standing program with the MLO Subjects underwent 8 weeks of gait training after construction of a custom MLO. There were three sessions per week of $2 \mathrm{~h}$ duration with the new orthosis. The gait training program also consisted of a period of trunk, upper limb and lower limb stretching, balancing while using the orthosis, and finally standing and walking.
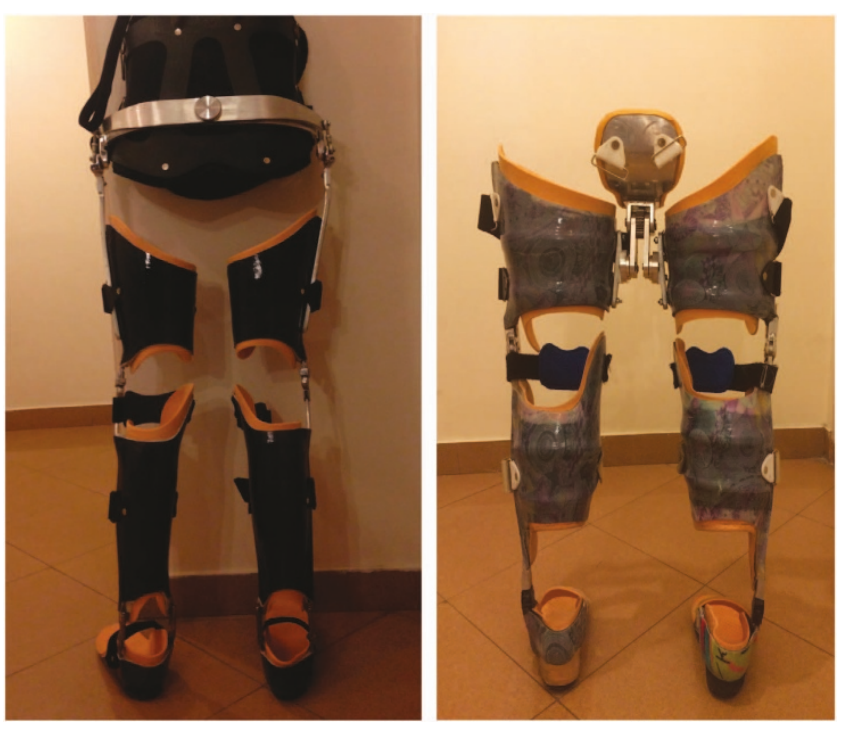

Figure 1. The orthoses that were used in this study.

Experimental protocol

The 6-min walk test was used in this study. Patients were asked to wear the two orthoses randomly and walk at their self-selected speed three times for a duration of 6 min over a 40-m length while their speed of walking was calculated by a stop watch.

A Polar heart rate monitor was used to compute the heart rate at steady state walking (HRss) and the heart rate at rest (HRar), and the physiological cost index $(\mathrm{PCl})$ was calculated using the following formula:

$$
\mathrm{PCl}\left(\text { beats } \mathrm{min}^{-1}\right)=(\text { HRss }-\mathrm{HRar}) / \mathrm{V}
$$

where $V$ is the walking speed. 


\section{RESULTS}

Table 2 reports the row data of $\mathrm{PCl}$, distance, speed of walking and heart rate during the two walking conditions (walking with IRGO and with the new MLO). Walking with the MLO improved the speed of walking; distance walked and reduced $\mathrm{PCl}$ as compared with walking with an IRGO as a control condition (Table 2).

\section{DISCUSSION}

Previous studies have reported unusually high energy requirements of walking with orthoses in paraplegic patients. The high energy requirement is probably the primary deterrent for walking with orthosis by this population. ${ }^{1,2,8,13}$ Powered orthoses and orthoses with functional electrical stimulation (FES) are more effective than mechanical orthoses in this regard, but these types of orthoses are heavy, bulky, expensive and cumbersome, so patients do not use them and prefer to use mechanical orthoses. ${ }^{6}$

In this case series we investigated energy expenditure between two kinds of mechanical orthoses (the new MLO and IRGO) in patients with lower limb paraplegia. The MLO is a new orthosis that was introduced recently and evaluated by a lower-limb paralysis simulator. Its effectiveness at achieving improved gait parameters compared with an IRGO was demonstrated in a paraplegic patient. ${ }^{11}$

Walking with MLO demonstrated a lower $\mathrm{PCl}$ value compared with an IRGO. Other researchers have advised changing the source of potential energy for activating the leg for forward propulsion. ${ }^{2,14}$ Bernardi et al. ${ }^{13}$ reported that trunk bending to provide hip flexion can increase energy. In the new orthosis, pelvic motion activates hip flexion, which requires less energy expenditure than the trunk extension needed for ambulation with an IRGO. ${ }^{11}$ The saddle plate proximal to the medial hip-joint bears a large portion of patients' weight and, as a result, a smaller amount of energy is expended for bearing weight by the upper limbs. Johnson et al. ${ }^{2}$ reported that increased loading on the upper limbs was the primary reason for high-energy expenditure in paraplegic patients. Also, lower weight and bulk could be contributing factors for the lower energy expenditure with the MLO observed in this study. Compared with literature in this field, Middleton et al. ${ }^{15}$ compared the walkabout (WA) and Moorong MLO and found that subjects ambulating with both orthoses had the same $\mathrm{PCl}\left(11.5\right.$ beats $\left.\mathrm{min}^{-1}\right)$, but the mean heart rate of subjects while using the Moorong MLO was less than that of subjects using the WA (155 and 164 beats $\min ^{-1}$ ). Saitoh et al. ${ }^{16}$ evaluated the effect of WA on five paraplegic patients and found that the mean 02 cost was $9.61 \mathrm{ml} \mathrm{kg}^{-1} \mathrm{~m}^{-1}$.

The mean speed of walking was higher in subjects using MLO compared with the IRGO. The walking speeds were similar compared with previous studies in this field, but knowing that higher speeds can be achieved with the MLO is noteworthy. In comparison between the WA and IRGO, Harvey demonstrated that wearing IRGO had higher speed of walking and less-energy consumption in paraplegic patients (IRGO: $0.19 \mathrm{~m} \mathrm{~s}^{-1}$, WA: $\left.0.09 \mathrm{~m} \mathrm{~s}^{-1}\right){ }^{17}$ It seems that the design of new MLO can facilitate ambulation while reducing effort, contributing to the higher speed of walking with this new orthosis. The mean of speed of walking using WA and Prime walk, as example of conventional MLOs, has been reported in literature. The mean of this parameter in comparison between hip and ankle linked orthosis (HALO) and Prime walk was 0.6 and $0.4 \mathrm{~m} \mathrm{~s}^{-1}$, respectively. ${ }^{18}$ In using Prime walk compared with WA, Onogi et al. ${ }^{19}$ reported that Prime walk had superiority in providing better result in speed of walking (PW:0.17 and WA:0.12 $\mathrm{m} \mathrm{s}^{-1}$ ). Middleton compared the Moorong MLO to WA and reported that the Moorong MLO increased the speed of walking compared with WA $\left(0.13\right.$ and $0.11 \mathrm{~m} \mathrm{~s}^{-1}$ respectively). ${ }^{15}$ In another study by Saitoh et al. ${ }^{16,20}$ the mean speed of walking while using the WA was reported to be
$0.33 \mathrm{~m} \mathrm{~s}^{-1}$. The mean speed in this current study was 0.33 and $0.39 \mathrm{~m} \mathrm{~s}^{-1}$ when IRGO and new MLO were used, respectively.

We used $\mathrm{PCl}$ for evaluating the energy expenditure in this study. This is a sensitive tool in assessment of gait for detecting small but significant differences in energy expenditure because of combining a physiological measurement (heart rate) and functional measurement (walking speed). Winchester et al. ${ }^{21}$ reported $\mathrm{PCl}$ of ambulating with an IRGO at a self-selected speed was lower than while using a standard RGO. Also, Leung et al. ${ }^{22}$ demonstrated that paraplegic patients with T12-L1 lesion have a lower PCl when they walk with an IRGO compared to when they walk with bilateral knee ankle foot orthosis (KAFOs).

The small sample size is a major limitation of this study because it was a case series. The subjects and assessors were not blind in this study. All subjects were experienced IRGO users. Also patients with different lesion levels participated in this study, so we suggest evaluating this new MLO on patients having similar physical characteristics and comparing gait parameters and stability while ambulating on their current orthoses. Also this new orthosis is more user friendly than RGOs, therefore it does not need someone to assist the user with donning and doffing, future studies in this field could evaluate larger sample size with stronger methodology and could measure functional independence and patients' acceptance.

\section{CONCLUSION}

In this case series, four paraplegic patients evaluated the effects of a new MLO compared with an IRGO on energy consumption and other gait parameters of interest. All subjects had faster speeds of walking, walked longer distances and had lower $\mathrm{PCl}$ values when using the new MLO compared to walking with the IRGO. More research in this field is needed.

\section{ACKNOWLEDGEMENTS}

We thank Dr Steven A Gard for his advice and comments. We also thank the University of Social Welfare and Rehabilitation Sciences for financial support for this research.

\section{DATA ARCHIVING}

There were no data to deposit.

\section{COMPETING INTERESTS}

The authors declare no conflict of interest.

\section{REFERENCES}

1 Bernardi M, Macaluso A, Sproviero E, Castellano V, Coratella D, Felici F et al. Cost of walking and locomotor impairment. J Electromyogr Kinesiol 1999; 9: 149-157.

2 Johnson WB, Fatone S, Gard SA. Walking mechanics of persons who use reciprocating gait orthoses. J Rehabil Res Dev 2009; 46: 435-446.

3 Franceschini M, Baratta S, Zampolini M, Loria D, Lotta S. Reciprocating gait orthoses: a multicenter study of their use by spinal cord injured patients. Arch Phys Med Rehabil 1997; 78: 582-586.

4 Scivoletto G, Petrelli A, Di Lucente L, Giannantoni A, Fuoco U, D'AMBROSIO F et al. One year follow up of spinal cord injury patients using a reciprocating gait orthosis: preliminary report. Spinal Cord 2000; 38: 555-558.

5 Sykes L, Edwards J, Powell E, Ross E. The reciprocating gait orthosis: long-term usage patterns. Arch Phys Med Rehabil 1995; 76: 779-783.

6 Arazpour M, Samadian M, Bahramizadeh M, Joghtaei M, Maleki M, Bani MA et al. The efficiency of orthotic interventions on energy consumption in paraplegic patients: a literature review. Spinal Cord (e-pub ahead of print 20 January 2015; doi:10.1038/sc.2014.227).

7 Arazpour M, Bani M, Hutchins S, Jones R. The physiological cost index of walking with mechanical and powered gait orthosis in patients with spinal cord injury. Spinal Cord 2014; 51: 356-359. 
8 Kawashima N, Sone Y, Nakazawa K, Akai M, Yano H. Energy expenditure during walking with weight-bearing control (WBC) orthosis in thoracic level of paraplegic patients. Spinal Cord 2003; 41: 506-510.

9 Arazpour M, Bani MA, Hutchins SW. Reciprocal gait orthoses and powered gait orthoses for walking by spinal cord injury patients. Prosthet Orthot Int 2013; 37 14-21.

10 Ahmadi Bani M, Arazpour M, Farahmand F, Mousavi ME, Hutchins SW. The efficiency of mechanical orthoses in affecting parameters associated with daily living in spinal cord injury patients: a literature review. Disabil Rehabil Assist Technol 2014; 10: 183-190.

11 Bani MA, Arazpour M, Farahmand F, Sefati S, Baniasad M, Hutchins S et al. Design and analysis of a new medial reciprocal linkage using a lower limb paralysis simulator. Spinal Cord 2014; 53: 380-386.

12 Bani MA, Arazpour M, Farahmand F, Azmand A, Hutchins S, Kashani RV et al. The influence of new reciprocating link medial linkage orthosis on walking and independence in a spinal cord injury patient. Spinal Cord 2015; 53(Suppl 1): S10-S12.

13 Bernardi M, Canale I, Castellano V, Di Filippo L, Felici F, Marchetti M. The efficiency of walking of paraplegic patients using a reciprocating gait orthosis. Paraplegia 1995; 33: 409-415.

14 Bernardi M, Macaluso A, Sproviero E, Castellano V, Coratella D, Felici F et al. Cost of walking and locomotor impairment. J Electromyogr Kinesiol 1999; 9 149-157.
15 Middleton J, Fisher W, Davis G, Smith R. A medial linkage orthosis to assist ambulation after spinal cord injury. Prosthet Orthot Int 1998; 22: 258-264.

16 Saitoh E, Baba M, Sonoda S, Tomiya Y, Suzuki M, Hayashi M (eds). A New Medial Single Hip Joint for Paraplegic Walkers 1997; 75: 198-203.

17 Harvey L, Davis G, Smith M, Engel S. Energy expenditure during gait using the walkabout and isocentric reciprocal gait orthoses in persons with paraplegia. Arch Phys Med Rehabil 1998; 79: 945-949.

18 Genda E, Oota K, Suzuki Y, Koyama K, Kasahara T. A new walking orthosis for paraplegics: hip and ankle linkage system. Prosthet Orthot Int 2004; 28: 69-74.

19 Onogi K, Kondo I, Saitoh E, Kato M, Oyobe T. Comparison of the effects of sliding-type and hinge-type joints of knee-ankle-foot orthoses on temporal gait parameter in patients with paraplegia. Jpn J Compr Rehabil Sci 2010; 1: 1-6.

20 Saitoh E, Suzuki T, Sonoda S, Fujitani J, Tomita Y, Chino N. Clinical Experience With A New Hip-Knee-Ankle-Foot Orthotic System Using A Medial Single Hip Joint for Paraplegic Standing and Walking1. Am J Phys Med Rehabil 1996; 75: 198.

21 Winchester P, Carollo J, Parekh R, Lutz L, Aston J. A comparison of paraplegic gait performance using two types of reciprocating gait orthoses. Prosthet Orthot Int 1993; 17: 101-106.

22 Leung A, Wong A, Wong $E$, Hutchins $S$. The physiological cost index of walking with an isocentric reciprocating gait orthosis among patients with T 12-L 1 spinal cord injury. Prosthet Orthot Int 2009; 33: 61-68. 